\section{OPEN ACCESS}

Edited by: Patrizia d'Ettorre, Université Paris 13, France

Reviewed by:

Abraham Hefetz,

Tel Aviv University, Israel

David Baracchi,

University of Florence, Italy

*Correspondence: Ken Sasaki

sasakik@agr.tamagawa.ac.jp

Specialty section:

This article was submitted to

Social Evolution,

a section of the journal

Frontiers in Ecology and Evolution

Received: 27 January 2021 Accepted: 21 April 2021

Published: 13 May 2021

Citation:

Sasaki K, Okada Y, Shimoji H, Aonuma H, Miura T and Tsuji K (2021)

Social Evolution With Decoupling of Multiple Roles of Biogenic Amines Into Different Phenotypes in Hymenoptera.

Front. Ecol. Evol. 9:659160. doi: 10.3389/fevo.2021.659160

\title{
Social Evolution With Decoupling of Multiple Roles of Biogenic Amines Into Different Phenotypes in Hymenoptera
}

\section{Ken Sasaki ${ }^{1 *}$, Yasukazu Okada ${ }^{2}$, Hiroyuki Shimojii ${ }^{3}$, Hitoshi Aonuma ${ }^{4}$, Toru Miura ${ }^{5}$ and Kazuki Tsuji ${ }^{6}$}

${ }^{1}$ Graduate School of Agriculture, Tamagawa University, Tokyo, Japan, ${ }^{2}$ Department of Biological Sciences, Tokyo Metropolitan University, Hachioji, Tokyo, Japan, ${ }^{3}$ Department of Bioscience, School of Science and Technology, Kwansei Gakuin University, Nishinomiya, Japan, ${ }^{4}$ Research Center of Mathematics for Social Creativity, Research Institute for Electronic Science, Hokkaido University, Sapporo, Japan, ${ }^{5}$ Misaki Marine Biological Station, School of Science, The University of Tokyo, Kanagawa, Japan, ${ }^{6}$ Department of Agro-Environmental Sciences, Faculty of Agriculture, University of the Ryukyus, Okinawa, Japan

Convergent evolution of eusociality with the division of reproduction and its plastic transition in Hymenoptera has long attracted the attention of researchers. To explain the evolutionary scenario of the reproductive division of labor, several hypotheses had been proposed. Among these, we focus on the most basic concepts, i.e., the ovarian ground plan hypothesis (OGPH) and the split-function hypothesis (SFH). The OGPH assumes the physiological decoupling of ovarian cycles and behavior into reproductive and nonreproductive individuals, whereas the SFH assumes that the ancestral reproductive function of juvenile hormone $(\mathrm{JH})$ became split into a dual function. Here, we review recent progress in the understanding of the neurohormonal regulation of reproduction and social behavior in eusocial hymenopterans, with an emphasis on biogenic amines. Biogenic amines are key substances involved in the switching of reproductive physiology and modulation of social behaviors. Dopamine has a pivotal role in the formation of reproductive skew irrespective of the social system, whereas octopamine and serotonin contribute largely to non-reproductive social behaviors. These decoupling roles of biogenic amines are seen in the life cycle of a single female in a solitary species, supporting $\mathrm{OGPH}$. JH promotes reproduction with dopamine function in primitively eusocial species, whereas it regulates non-reproductive social behaviors with octopamine function in advanced eusocial species. The signal transduction networks between $\mathrm{JH}$ and the biogenic amines have been rewired in advanced eusocial species, which could regulate reproduction in response to various social stimuli independently of $\mathrm{JH}$ action.

Keywords: biogenic amine, division of labor, eusociality, Hymenoptera, reproduction, social evolution 


\section{INTRODUCTION}

Eusociality in insects, characterized by sophisticated division of labor among group members, is assumed to have evolved convergently from non-eusocial ancestors in an individual taxon such as Hymenoptera (bees, wasps, and ants), Blattodea (termites), Hemiptera (aphids), Thysanoptera (thrips), and Coleoptera (beetles) (reviewed by Berens et al., 2015; Toth and Rehan, 2017; Costa, 2018). The insect eusociality is defined by cooperative brood care, overlapping generations between the parent and adult offspring, and a reproductive division of labor (castes) (Wilson, 1971). Based on the stability of castes and the degree of morphological dimorphism between castes, eusociality in Hymenoptera is further divided into three groups: facultative, primitive and advanced eusociality (Hunt, 2012). Facultative eusociality is characterized by a flexible presence in the non-morphological castes. In primitive eusociality, the non-morphological castes are always present, and behaviorally distinct and plastic, whereas advanced eusocial organisms with rigid morphological castes probably originated from primitive eusociality (Hunt, 2012; Jandt and Toth, 2015; Toth and Rehan, 2017).

To explain the evolutionary process of eusociality from solitary to advanced eusociality in Hymenoptera, several mechanistic hypotheses for social evolution have been proposed (West-Eberhard, 1996; Robinson and Vargo, 1997; Hunt, 2007; Jandt and Toth, 2015). We introduce two evolutionary hypotheses involved in reproductive physiology. First is the ovarian ground plan hypothesis (OGPH), which focuses on the physiological decoupling of ovarian cycles and behavior into reproductive and non-reproductive states (West-Eberhard, 1996). This hypothesis comprises three components. The first is a proposed cycle of ovarian activity in a solitary ancestor of the social species. The second is the context-dependent expression of alternative behaviors from a single genotype (phenotypic plasticity) that can occur among females that nest together, each with a solitary ovarian ground plan. The third is the evolution of a switch-like mechanism that regulates phenotypic expression into two castes: queens and workers (West-Eberhard, 1996; Hunt, 2007). This hypothesis predicts that physiological characteristics related to caste-specific behavior in eusocial species are similar to those of reproductive and non-reproductive behavior in a single female in a solitary species (West-Eberhard, 1996; Jandt and Toth, 2015; Trumbo, 2018). A related hypothesis termed the reproductive ground plan hypothesis $(\mathrm{RGPH})$ posits that the regulation of the division of labor among workers arose from a further split of solitary gene networks related to reproduction (Amdam et al., 2004; Amdam and Page, 2010). The present paper discusses the evolutionary process of the reproductive division of labor from solitary to advanced eusociality, which is more related to OGPH than RGPH.

Second is the split-function hypothesis ( $\mathrm{SFH}$ ) that focuses on the function of juvenile hormone (JH) (West-Eberhard, 1996; Robinson and Vargo, 1997; Jandt and Toth, 2015). $\mathrm{JH}$ is a hemolymphatic hormone released from corpora allata and is well known as a key factor regulating the female reproductive state in solitary insects (Nijhout, 1994;
Hartfelder, 2000; Raikhel et al., 2005; Jindra et al., 2013). In primitive eusocial Hymenoptera, including paper wasps and bumble bees, JH promotes ovarian development and egg-laying behavior as well as solitary species (Robinson and Vargo, 1997; Tibbetts et al., 2011a; Shpigler et al., 2014; Figure 1). In contrast, in advanced eusocial species, including honey bees and ants, high $\mathrm{JH}$ titer is associated with an age-related behavioral shift from nursing to foraging (Robinson and Vargo, 1997; Bloch et al., 2009; Figure 1). These findings lead to the suggestion that $\mathrm{JH}$ function has shifted from a gonadotropin to a behavioral regulator in workers during the social evolution. The SFH assumes that the ancestral reproductive function of $\mathrm{JH}$ became split into a dual function, regulating reproduction in queens and behavioral division of labor among workers (i.e., nest construction, nursing, defense, and foraging), and in advanced eusocial species, the reproductive function of $\mathrm{JH}$ might have been lost. Therefore,

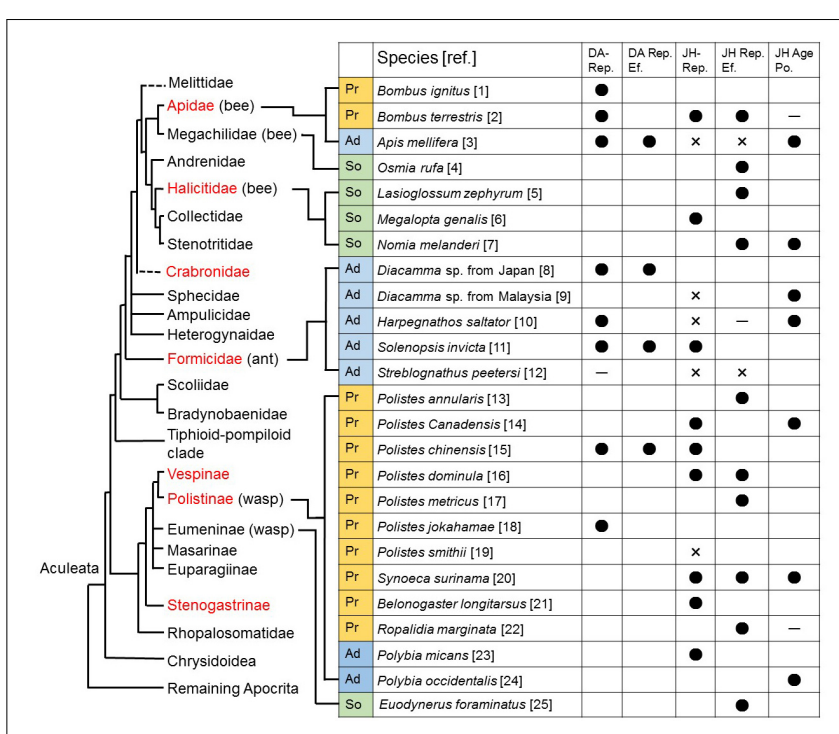

FIGURE 1 | Roles of dopamine and juvenile hormone in reproductive females in Hymenoptera. A phylogenetic tree based on Gullan and Cranston (2014) is modified. Possible non-monophyletic families are shown in quotes on a dashed branch. Families containing eusocial species are indicated in red. In this figure, evidence of correlation and causal relationships are extensively evaluated. Correlation between dopamine levels in the brains and reproduction (DA-Rep.), and between juvenile hormone titers in hemolymph and reproduction (JH-Rep.) are indicated as positive $(\bullet)$, negative $(\times)$, and neutral (-). Effects of dopamine (DA Rep. Ef.) and juvenile hormone (JH Rep. Ef.) on reproduction, the relation of juvenile hormone with age polyphenism (JH Age Po.) are also indicated. Ad: advanced eusocial, Pr: primitively eusocial, So: solitary and facultatively eusocial (Bohm, 1972; Bell, 1973; Barth et al., 1975; Röseler, 1977; Robinson et al., 1992; O’Donnell and Jeanne, 1993; Sommer et al., 1993; Harris and Woodring, 1995; Robinson and Vargo, 1997; Bloch et al., 2000; Pinto et al., 2000; Boulay et al., 2001; Sasaki and Harada, 2020; Agrahari and Gadagkar, 2003; Brent and Vargo, 2003; Dombroski et al., 2003; Cuvillier-Hot et al., 2004; Giray et al., 2005; Brent et al., 2006; Cuvillier-Hot and Lenoir, 2006; Sasaki et al., 2007, 2009; Penick et al., 2011; Tibbetts et al., 2011b; Wasieleski et al., 2011; Tibbetts et al., 2013a; Smith et al., 2013; Amsalem et al., 2014; Kelstrup et al., 2014a; Kelstrup et al., 2014b; Penick et al., 2014; Shpigler et al., 2014; Kelstrup et al., 2015, 2017; Okada et al., 2015; Kapheim and Johnson, 2017; Sasaki et al., 2017; Tsuchida et al., 2020; Yoshimura et al., 2021). 
this hypothesis predicts that $\mathrm{JH}$ regulates reproduction only in solitary species, and regulates both reproduction and division of labor among workers in primitive eusocial species (WestEberhard, 1996; Jandt and Toth, 2015).

To re-evaluate the SFH and OGPH, we focus on the substances that directly regulate neural activities for social behavior. Social behavior is largely regulated by several types of interaction among colony members (e.g., dominance interactions, pheromones, or trophallaxis). These stimuli are neurally inputted as multimodal sensory signals and processed in the central nervous system (CNS). The behavioral outputs are adaptively plastic, depending on the colony status. Therefore, the neural process-behavioral output pathway might not be as fixed as expected, but instead be flexibly selected from available multiple pathways or combined multiple pathways in the CNS by neural modifiers. One such group of neural modifiers is the biogenic amines. Biogenic amines are neuroactive substances that elicit certain behaviors and physiological states and are widely conserved among vertebrates and invertebrates. They have roles as neurotransmitters (acting on a synapse), neuromodulators (acting on local neural circuits), and neurohormones (hormonal function in remote tissues) in both the peripheral nervous system and CNS (Evans, 1980; Roeder, 2005; Lange, 2009). Thus, they are probably the fundamental factors mediating social interactions and the output of social behaviors.

Recently, there has been a significant increase in the number of physiological studies on social behaviors (especially in social hymenopterans) and the results have suggested the regulatory mechanisms of biogenic amines together with roles of $\mathrm{JH}$ and environmental factors. Therefore, here we integrate recent data on biogenic amines and other factors to highlight connections between biogenic amines and social behavior in eusocial hymenopterans, leading to an improved understanding of social evolution.

\section{REPRODUCTIVE DIVISION OF LABOR AND WORKER REPRODUCTION}

The reproductive division of labor is fundamental to the organization and evolution of insect societies. In primitive eusocial hymenopterans, the caste fate can be mainly determined at the adult stage, with a pre-imaginal bias generated at the larval stage (O’Donnell, 1998; Berens et al., 2015). In Polistes wasps, the cues related to caste determination during the preimaginal stage include levels of larval nutrition and frequency of vibrational stimuli (O’Donnell, 1998; Suryanarayanan et al., 2011). The cues during the adult stage are the presence of a queen and photoperiods (Bohm, 1972; Solís and Strassmann, 1990; Yoshimura et al., 2021).

In advanced eusocial societies, including honey bees, stingless bees, and most ants, reproduction is strongly biased toward queens. Queens have a high reproductive ability relative to workers, which are either sterile or have low reproductive potential. Caste-specific developmental pathways depending on the nutritional condition during the larval stages might, to some degree, result in two adult phenotypes (Wilde and Beetsma,
1982; Asencot and Lensky, 1988; Kamakura, 2011; Leimer et al., 2012; Corona et al., 2016) and a specialized adult brain that is morphologically and physiologically adapted to the performance of caste-specific behavioral tasks (Snodgrass, 1956; Michener, 1974; Arnold et al., 1988; Groh and Rössler, 2008). How the castespecific behaviors are physiologically regulated is an important issue in the reproductive division of labor in social insects. The details of such caste-specific physiology would provide us with a key to further our understanding of social evolution.

\section{Reproductive Function of $\mathbf{J H}$}

In primitive eusocial Hymenoptera, $\mathrm{JH}$ promotes ovarian development and egg-laying behavior at adult stages as well as in solitary species (Raikhel et al., 2005; Tibbetts et al., 2011a; Shpigler et al., 2014). Whereas, in advanced eusocial species, JH inhibits the synthesis of a precursor of egg yolk vitellogenin or does not affect ovarian development (Robinson and Vargo, 1997; Pinto et al., 2000; Bloch et al., 2009; Figure 1). These findings well fit the SFH that the ancestral reproductive function of $\mathrm{JH}$ became split into a dual function, regulating reproduction in queens and behavioral division of labor among workers. In contrast, this evidence does not support the OGPH, because $\mathrm{JH}$ reproductive function is no longer conserved in reproductive individuals in advanced eusocial species. In advanced eusocial species, it is expected that other substances instead of $\mathrm{JH}$ may drive cascades of ovarian development for reproduction.

\section{Caste-Specific Behaviors Mediated by Biogenic Amines}

Queen-worker differences in dopamine levels in the brain have been reported in several species including the bumble bee Bombus ignitus (Sasaki et al., 2021) and the honey bee Apis mellifera (Brandes et al., 1990; Sasaki et al., 2012, 2018), but not found in some ants (e.g., Formica japonica, Aonuma and Watanabe, 2012a). In the bumble bee, the dopamine levels in the brains of emerged queens (gynes) are approximately two times higher than in emerged workers (Sasaki et al., 2021). The levels of the precursor and metabolite of dopamine are also higher in queens, suggesting the upregulation of the synthetic pathway of dopamine in the brain of the queen. In the honey bee, the dopamine levels in the brains of virgin queens were 3.5-7 times higher than that in the same aged workers (Sasaki et al., 2012, 2018). The caste differences in dopamine levels in the brain occur during pupal stages with upregulation of gene expression of enzymes involved in dopamine biosynthesis (Sasaki et al., 2018). From the larval stage to the adult stage, nurse bees provide queens with food known as "royal jelly," which contains the dopamine precursor tyrosine (Haydak, 1970; Liming et al., 2009). Artificial feeding of royal jelly during the larval stage increases tyrosine flow with an elevation of catecholamines including dopamine in the brain of queen-like adult females (Sasaki and Harada, 2020).

In honey bees, the high levels of dopamine in both brain and hemolymph in virgin queens can contribute to the enhancement of fighting with rival nestmate queens (Farkhary et al., 2017; Sasaki and Harada, 2020), locomotor activities (Harano et al., 2008), and flight activities (Farkhary et al., 2019), which could 
lead to active mating flight. In the fire ant, Solenopsis invicta, virgin queens shed their wings (dealation) and lay unfertilized male eggs in response to their isolation from nestmates. The isolated virgin queens have higher dopamine levels in their brains than the same aged non-isolated virgin queens (Boulay et al., 2001). The inhibition of tyrosine hydroxylase for dopamine biosynthesis reduced egg production, whereas restoring dopamine biosynthesis with a dopamine precursor restored oogenesis and oviposition, suggesting that dopamine promotes reproduction (Boulay et al., 2001). Thus, dopaminergic activities seem to be one of the conserved physiological characteristics in the brain of the reproductive caste in bees and ants, although more evidence is required in other species across multiple levels of eusociality.

\section{Worker Reproduction and Dominance Hierarchy Among Females}

In many advanced eusocial hymenopterans, workers cannot mate despite retaining functional ovaries and producing unfertilized eggs that develop parthenogenetically into males. Although workers are usually infertile with inactivated ovaries in the presence of a queen, worker reproduction frequently occurs in the absence of queens. Even in facultative and primitive eusocial species, subordinate reproduction can be suppressed behaviorally and pheromonally by dominant females in a similar way to the suppression of worker reproduction in advanced eusocial species. Recent literature suggests consistently that brain dopamine is involved in the behavioral and physiological transitions of nonreproductives to reproductives in several lineages (Figures 1, 2). Dopamine levels in the brains are positively correlated with the reproductive states of workers in bumble bees (B. terrestris: Bloch et al., 2000; B. ignitus: Sasaki et al., 2017), paper wasps (Polistes chinensis: Sasaki et al., 2007; Polistes jokahamae: Yoshimura et al., 2021), the honey bee A. mellifera (Harris and Woodring, 1995; Sasaki and Nagao, 2001), and reproductive females (gamergates) in ant species that retain totipotent workers (Harpegnathos saltator, Penick et al., 2014; Diacamma sp., Okada et al., 2015; Figure 1). Experimental manipulations using dopamine suggested gonadotropic functions and activation of ovaries in workers of A. mellifera (Dombroski et al., 2003), P. chinensis (Sasaki et al., 2009), and Diacamma sp. (Okada et al., 2015). The combination of this correlative evidence with the experimental evidence suggests that the reproductive function of dopamine is shared among several species in multiple eusocial lineages in Hymenoptera.

The gene expression of dopamine receptors in the brains or ovaries of reproductive workers can be influenced by queen substances in A. mellifera (Beggs et al., 2007; Vergoz et al., 2012) and by isolation from interactions with nestmates in H. saltator (Penick et al., 2014) and Diacamma sp. (Okada et al., 2015; Shimoji et al., 2017; Figure 3). In the honey bee, two dopamine receptor genes, Amdop1 (DopR1) and Amdop2 (DopR2) decrease in the brains of reproductive workers (Vergoz et al., 2012; Figure 3). Since the expression of Amdop1 and Amdop2 in the brains of virgin queens are lower than in normal workers (Sasaki et al., 2018), the downregulation of

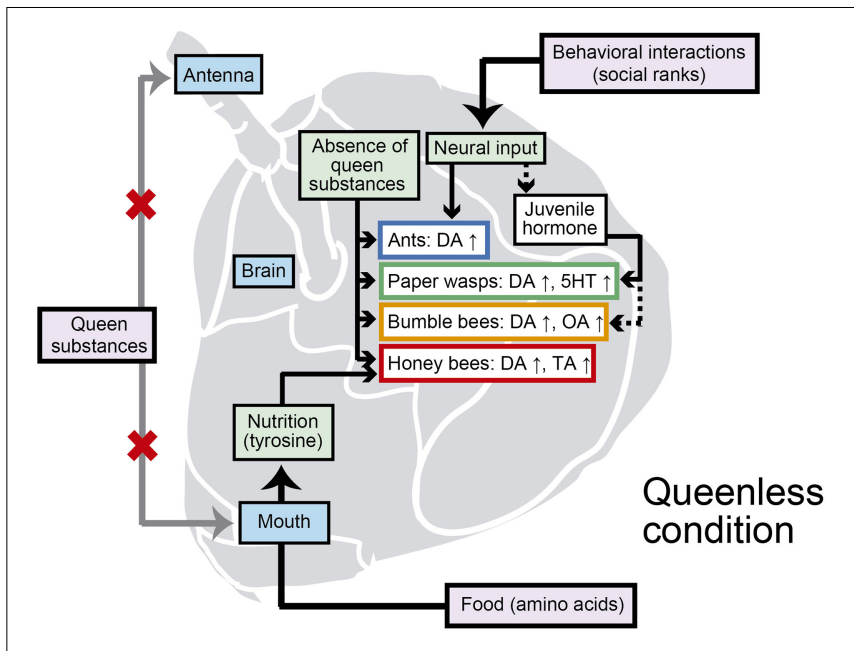

FIGURE 2 | Factors affecting increases in biogenic amines in the brain during the transition of non-reproductives to reproductives in Hymenoptera. Purple boxes indicate environmental factors. Dashed lines indicate hypothetical pathways. DA: dopamine, OA: octopamine, TA: tyramine, 5HT: serotonin. In this summary, "queen" and "queenless" are used in a broad sense to include functional queens in ants (i.e., gamergates).

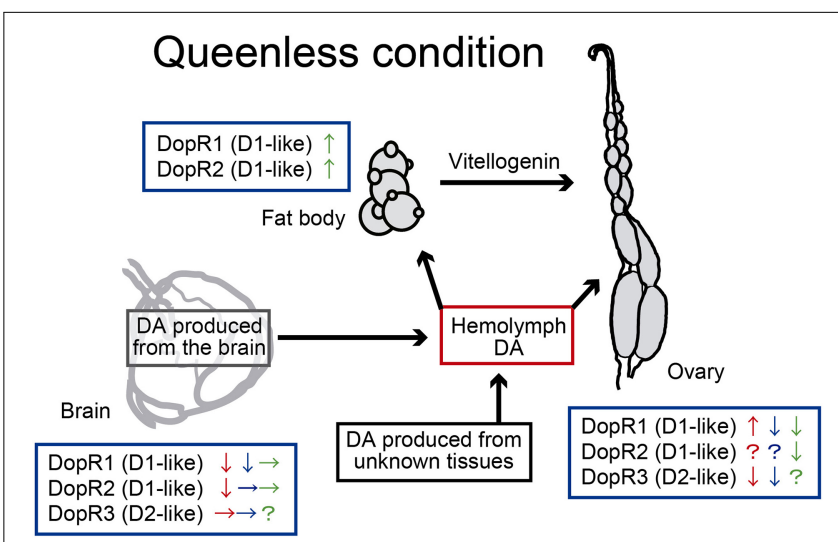

FIGURE 3 | Gene expression of dopamine receptors in the brain and peripheral tissues of reproductive workers. Red: Apis mellifera, blue: Harpegnathos saltator, green: Diacamma. sp. The expression levels of receptor genes are based on Vergoz et al. (2012); Penick et al. (2014), and Okada et al. (2015). In this summary, "queen" and "queenless" are used in a broad sense to include functional queens in ants (i.e., gamergates).

these genes in reproductive workers suggests a transition to a queen-like state. In a monomorphic ant Diacamma, D1like (human dopamine receptor subtype 1-like) receptor genes (dopr1 and dopr2) are abundant in fat bodies of gamergates (Okada et al., 2015), suggesting that the fat body is a potential target of dopamine to stimulate vitellogenin (Vg) synthesis for ovarian activation (Figure 3 ). Thus, the expression of dopamine receptors in the brains and peripheral organs involved in ovarian development supports the gonadotropic neurohormonal function of dopamine.

Although dopamine has a predominant gonadotropic function across taxa, brain tyramine might also promote 
reproduction with dopamine in workers in the honey bee. The levels of brain tyramine in worker honey bees increase with dopamine in response to the removal of a queen (Sasaki and Nagao, 2002). The oral application of tyramine can inhibit flying for foraging (Schulz and Robinson, 2001; Fussenecker et al., 2006) and promote ovarian activity (Sasaki and Harano, 2007) and the production of queen-like pheromones by Dufour's gland and the mandibular glands (Salomon et al., 2012). In the paper wasp $P$. jokahamae, the long-day photoperiod condition increases the tyramine level in the brain and causes the initiation of ovarian development (Yoshimura et al., 2021). In this paper wasp, the levels of tyramine and dopamine in the brains are correlated with ovarian development (Yoshimura et al., 2021). Thus, mediation by both dopamine and tyramine, which have a common precursor tyrosine, suggests the involvement of tyrosine in ovarian activation. Later in this article, we focus on current advances in understanding the environmental and physiological regulation of dopamine, as a pivotal orchestrator of reproductive physiology and behavior.

\section{Social Factors Affecting Dopamine Levels in the Brain}

Determining the regulatory mechanisms underlying an increase in brain dopamine depending on the social environment is important for understanding the regulation of reproduction in eusocial species. Several pioneering studies have begun to elucidate various environmental and social factors involved in the regulatory mechanisms (Beggs et al., 2007; Penick et al., 2014; Matsuyama et al., 2015; Shimoji et al., 2017). Behavioral interactions (dominance interaction), pheromonal signals (queen substances), and nutrition (food intake) are plausible candidates in the influence of brain dopamine levels that control reproductive states (Figure 2).

\section{Dominance Interaction}

In behavioral interactions, aggressive behavior can influence reproductive states among females. In primitive eusocial species, social ranks including pre-contest assessment behavior and reproductive states are associated with $\mathrm{JH}$ titer (Röseler, 1977; Giray et al., 2005; Tibbetts et al., 2013b; Tsuchida et al., 2020). Given that dopamine is also related to reproductive states in primitive eusocial species (Bloch et al., 2000; Sasaki et al., 2007, 2017; Yoshimura et al., 2021), a relationship between $\mathrm{JH}$ and dopamine is expected. In fact, the application of $\mathrm{JH}$ can enhance the dopamine levels in the brain of workers in the paper wasp $P$. chinensis (Tsuchida et al., 2020). In contrast, the reproductive roles of $\mathrm{JH}$ have been lost in several advanced eusocial species (Figure 1; Robinson and Vargo, 1997; Bloch et al., 2009), such that other substances downstream of $\mathrm{JH}$, including dopamine, might have a function in promoting reproduction.

In the ant $H$. saltator, after being subjected to aggressive behaviors by nestmates, workers have lower dopamine levels in their brains compared with those nestmates (Penick et al., 2014). In Diacamma sp., dominant workers that aggress other workers have higher dopamine levels in their brains compared with lower-ranked subordinate workers (Shimoji et al., 2017). Such subordinate workers have elevated levels of brain dopamine after isolation from the dominant workers and thus are no longer subjected to attack. These observations suggest that dopamine in the brain is regulated by aggressive behavior (Shimoji et al., 2017; Figure 2). The level of dopamine increases in the brain of the winner of an aggressive interaction to activate her ovaries, whereas the loser decreases the level of brain dopamine to suppress ovarian activation. If the brain dopamine level or the ovarian activity positively influences their aggressiveness, a positive feedback process can finally lead to the monopolization of reproduction by a particular female. However, physiological factors determining the level of aggressiveness in dominance interactions are yet to be investigated.

\section{Queen Substances}

Queen substances can control worker behavior and physiology in advanced eusocial bees as pheromonal signals. In the honey bee, a queen pheromone, homovanillyl alcohol (HVA), can reduce brain dopamine levels (Beggs et al., 2007). HVA has the potential to bind a dopamine receptor (AmDOP3) and to act as an agonist (Beggs and Mercer, 2009). HVA can control brain dopamine in two ways: the first is the detection of HVA by antennae and the resulting transmission of neural signals to influence brain dopamine; the second is via the oral intake of HVA so that it can act directly on the dopaminergic systems in the brain via the hemolymph (Figure 2). The former is supported by results showing the neural processing of chemosensory signals from queen substances in the antennal lobes (Carcaud et al., 2015). Another component of queen substances in the honey bee, (2E)-9-oxodecenoic acid (9ODA), also has important functions to inhibit ovarian activation in workers and is detected by antennae with particular odorant receptors and transduced as neural signals (Wanner et al., 2007). Although novel, the latter mechanism requires more evidence. Given that other chemicals (e.g., cuticular hydrocarbons) that can be sensed by antennae are used as queen substances in other hymenopteran species (e.g., Van Oystaeyen et al., 2014), the detection of queen substances by the antennae might be a common pathway (d'Ettorre et al., 2004), whereas the oral intake of queen substances might be an additional mechanism in the honey bee.

\section{Food Intake}

Food consumption is influenced by the presence of a queen and her brood in a colony and affects the supply of precursors of biogenic amines. In the honey bee, royal jelly contains tyrosine, which is a common precursor of dopamine, tyramine, and octopamine, although tyrosine is not the most abundant of the 26 amino acids that are contained in royal jelly (Townsend and Lucas, 1940; Haydak, 1970; Liming et al., 2009). Royal jelly is normally fed by nurse bees to the queen and larvae in the queenright colony, whereas, in queenless colonies without broods, it can be shared among nurse bees that can become reproductive individuals. Therefore, reproductive individuals in queenless colonies might ingest a relatively large amount of tyrosine by consuming royal jelly-like food. This intake of tyrosine can enhance the levels of brain dopamine and tyramine in queenless workers and accelerate their transition 
from normal workers to reproductive individuals (Matsuyama et al., 2015; Figure 2). This mechanism might operate not only in honey bees but also other social insects in which the brain dopamine levels either increase slowly in the absence of a queen or are maintained at a high level during reproduction. These species require nutrition for ovarian activation, with supplies of dopamine precursors. Thus, dopamine metabolism and signaling appear to have a pivotal role in the formation of reproductive skew across various social systems, i.e., from primitive societies in which physical interaction among monomorphic females regulates the reproductive division of labor to advanced societies where pheromones control it remotely.

\section{Reproductive Function of Dopamine in Solitary Insects}

The reproductive function of dopamine in solitary insects is a prerequisite for assuming dopamine as the core physiological system in OGPH. The OGPH assumes that ancestral solitary species possess functional aminergic systems for both reproductive and non-reproductive activities. The OGPH predicts that one functional system for reproduction expresses in reproductive females, the other non-reproductive system occurs in workers. Reproductive females in primitive and advanced eusocial hymenopterans seem to possess the dopaminergic system for reproduction as mentioned above.

Reproductive functions of the dopamine in females of solitary insects have been reported in Blattodea (cockroach Blattella germanica: Pastor et al., 1991), Hemiptera (linden bug Pyrrhocoris apterus: Chvalova et al., 2014; plant bug Lygus hesperus: Brent et al., 2016), Coleoptera (red flour beetle Tribolium castaneum: Bai and Palli, 2016), and Diptera (fruit fly Drosophila melanogaster: Neckameyer, 1996; Pendleton et al., 1996; mosquito Anopheles gambiae: Fuchs et al., 2014). In these species, dopamine accelerates ovarian development and egglaying behavior, often in a nutrition-dependent manner. In A. gambiae, the inhibition of tyrosine (a precursor of dopamine) supply causes a decrease in oviposition rate, fecundity, and egg hatching rate (Fuchs et al., 2014). In T. castaneum, the knockdown of the dopamine D2-like receptor gene leads to a reduction in vitellogenin accumulation in developing oocytes and an inhibition of JH-regulated remodeling of follicular epithelium, suggesting a dopamine function of ovarian maturation with $\mathrm{JH}$ mediation (Bai and Palli, 2016). In D. melanogaster, sexually mature females express higher D1-like receptor (DopR) in the fat body than young immature females (Gruntenko et al., 2012). This expression pattern of the D1-like receptor in the fat body is similar to that in the ant Diacamma (Okada et al., 2015). Dopamine also regulates mating behavior in D. melanogaster (Wicker-Thomas and Hamann, 2008). Dopamine production regulated by $\mathrm{JH}$ has been reported in the brains of females in D. melanogaster (Argue et al., 2013) and L. hesperus (Brent et al., 2016). Thus, the reproductive function of dopamine is shared among solitary species across different orders and could be an ancestral character as a functional system to promote reproduction with $\mathrm{JH}$.

\section{DIVISION OF LABOR AMONG WORKERS}

Workers change their tasks depending on their age, size, and/or morphology in the primitive and advanced eusocial hymenopterans. In contrast to the age-related division of labor which has been extensively studied in the honey bee, little is known about endocrine influences on the size-related division of labor that is seen commonly in ants and bumble bees. The size and morphology of workers performing different tasks are determined by developmental processes during the larval and pupal stages. Therefore, the size-related or morphological division of labor might be based on the particular physiological state of each subcaste after eclosion and can be modified by the states changing with age.

\section{JH Function Regulating Age-Related Division of Labor}

The physiological basis of the age-related division of labor has been studied extensively in honey bees. Younger bees perform tasks inside the nest, such as feeding larvae, constructing and maintaining the nest, and processing honey, whereas older bees guard the nest and forage (Winston, 1987). The onset of foraging in honey bees is linked to the action of JH (Robinson and Vargo, 1997; Bloch et al., 2009). JH titers in honey bee workers normally increase with age. Foraging worker bees have higher hemolymphatic JH titers than bees working in the nest. Treatment of young bees with methoprene, a JH analog, results in the initiation of foraging earlier in life. $\mathrm{JH}$ is produced in the corpora allata, paired secretory glands located close to the brain (Nijhout, 1994). Removal of the corpora allata resulted in bees that were able to initiate foraging although they were delayed in their foraging onset (Sullivan et al., 2000). These results not only demonstrate an effect of $\mathrm{JH}$ on age at onset of foraging but also show that $\mathrm{JH}$ is not necessary for the initiation and maintenance of foraging behavior. Therefore, it is likely that foraging onset in worker bees is governed by redundant control mechanisms. Such a JH function regulating the age-related division of labor has been reported in other advanced eusocial species such as the paper wasp Polybia occidentalis (O’Donnell and Jeanne, 1993) and some ants (Diacamma: Sommer et al., 1993; Harpegnathos saltator, Penick et al., 2011; Figure 1).

The $\mathrm{JH}$ function promoted foraging, including sugar response and learning has been reported in the solitary bee Nomia melanderi (Kapheim and Johnson, 2017) and the primitive eusocial paper wasp Polistes canadensis (Giray et al., 2005) and Synoeca surinama (Kelstrup et al., 2014b; Figure 1). Studies in the primitive eusocial species seem to support the SFH assuming the ancestral reproductive function of $\mathrm{JH}$ became split into a gonadotropin and a regulator of worker foraging in the primitive eusocial species. However, a study in $N$. melanderi did not support the SFH, because the hypothesis does not assume the ancestral foraging function by $\mathrm{JH}$, rather this foraging function of JH supports the OGPH (Kapheim and Johnson, 2017). Therefore, the conclusion that the evolutionary process of the $\mathrm{JH}$ function shifted from a gonadotropin to a regulator of worker foraging is still controversial. 


\section{Social Behaviors and Physiology Mediated by Biogenic Amines}

\section{From Nursing to Foraging}

Although nursing is a major task for workers in the nest, a clear involvement of biogenic amines in enhancing brood care has not been reported in hymenopterans, and increased levels of amines are more likely to be associated with extranidal tasks. An example of amine involvement in intranidal task regulation in honey bees could be tyramine and octopamine involvement in thermoregulatory fanning in the nest (Cook et al., 2017). The nursing behavior of worker honey bees occurs under lower levels of octopamine, dopamine, and serotonin, which increase in the brain with age under queenright conditions (Taylor et al., 1992; Schulz and Robinson, 1999). Interestingly, such age-related increases in these amines in the brains of workers are also observed in some ants, including Pheidole (Seid and Traniello, 2005), Diacamma (Okada et al., 2015), and the jumping ant Harpegnathos (Penick et al., 2014). For example, in Pheidole dentata, serotonin modulates minor worker responsiveness to trail pheromones (Muscedere et al., 2012). These facts suggest that the age-dependent increase in octopamine, dopamine, and serotonin is a shared pattern in worker behavioral ontogeny, at least in the honey bee and ants.

Octopamine in the brain is enhanced by $\mathrm{JH}$ and promotes foraging behaviors in the honey bee (Schulz and Robinson, 2001; Schulz et al., 2002). Octopamine can enhance the responses of nestmate recognition with aggression and learning in workers (Robinson et al., 1999; Farooqui, 2012), which could support guarding behaviors initially and then foraging behaviors that require learning and memory. Octopamine also mediates the persistent modulation of associative learning and memory induced by an attractive pheromone component geraniol (Baracchi et al., 2020). Expression of a gene encoding the octopamine receptor $(A m o c t \beta r 3 / 4)$ changes with age rather than with social task, whereas that of Amoctarl correlates with social tasks (Reim and Scheiner, 2014). Octopamine can also enhance sugar responses in the proboscis extension of the honey bee (Scheiner et al., 2002) and the stingless bee Melipona scutellaris (McCabe et al., 2017), which is a behavioral modulation for foraging characteristics. In fact, octopamine increases individual foraging effort and collective food source exploitation in the neotropical stingless bee Plebeia droryana (Peng et al., 2020). In terms of foraging behaviors, brain levels of octopamine are higher in dancing honey bees than in those that follow them, and octopamine selectively increases the reporting of resource value in dances by foragers (Barron et al., 2007).

\section{Aggression for Guarding or Predation}

The involvement of several biogenic amines in defensive or aggressive behaviors has been reported in social hymenopterans. Aggressive behaviors can be categorized into interactions within species (intraspecies) and between species (interspecies). The effects of amines in aggressive dominance interactions are discussed earlier (see section "Social Factors Affecting Dopamine Levels in the Brain"). Interspecies aggression can be further divided into attacks during foraging (predation), nest defense against predators, and competition between species. Octopamine is known to elevate aggression levels between conspecific males generally in solitary insects, including fruit flies (Baier et al., 2002) and crickets (Stevenson et al., 2005). These interactions between rival males might correspond to intraspecies interactions in social species. In honey bee workers, several octopamine agonists enhance the aggression levels during nestmate recognition (Robinson et al., 1999). Serotonin enhances the response to the alarm pheromone component (Harris and Woodring, 1999; Nouvian et al., 2018). In ants, octopamine and serotonin might be involved in aggressiveness in intraand interspecies interactions. Although the functional differences between octopamine and serotonin are unknown, there are positive correlations between aggressiveness and octopamine in intraspecies interactions in Oecophylla smaragdina (Kamhi et al., 2015), and in interspecies interactions in F. japonica (Aonuma and Watanabe, 2012b) and O. smaragdina (Kamhi et al., 2015), or between aggressiveness and serotonin in intraspecific interactions in Formica rufa (Kostowski and Tarchalska, 1972; Kostowski and Tarchalska-Krynska, 1975). In Odontomachus kuroiwae, oral administration of serotonin or its precursor strongly promotes the initiation of defensive behavior (Aonuma, 2020). In general, worker aggressiveness increases with age in social Hymenoptera. Together with the results discussed in the previous section, the age-dependent increase in biogenic amines might generally enhance the aggressiveness of workers, although there could also be context-dependent adjustments of aggression levels in these workers.

Cooperative behaviors in social insects can be observed under conditions of low aggressiveness among nestmates. In the ant Camponotus fellah, octopamine decreases the frequency of trophallaxis (food exchange) between nestmate workers, whereas the application of serotonin does not affect trophallactic frequencies, suggesting that octopamine has a stronger effect on trophallaxis than does serotonin (Boulay et al., 2000). In the ant Pristomyrmex punctatus, the intake of secretion of the myrmecophile butterfly Narathura japonica larvae causes a low level of brain dopamine that enhances the intensity of guarding behavior of workers to the latter (Hojo et al., 2015).

\section{DISCUSSION}

The OGPH assumes the decoupling of reproductive physiology into reproductive and non-reproductive states that are allocated to different individuals in eusocial species (WestEberhard, 1996). Given that biogenic amines have multiple roles in reproduction and general behavior, we expect that the involvement of biogenic amines in the regulation of physiological status between reproductives and non-reproductives is derived from the characteristics of the solitary ancestors of eusocial species (Kamhi et al., 2017; Figure 4). The reproductive physiology in primitive and advanced eusocial hymenopterans is broadly associated with dopamine in the brain (Figure 1, see section "Reproductive Division of Labor and Worker Reproduction"), whereas non-reproductive behaviors in advanced eusocial species, including foraging and nest defense, 


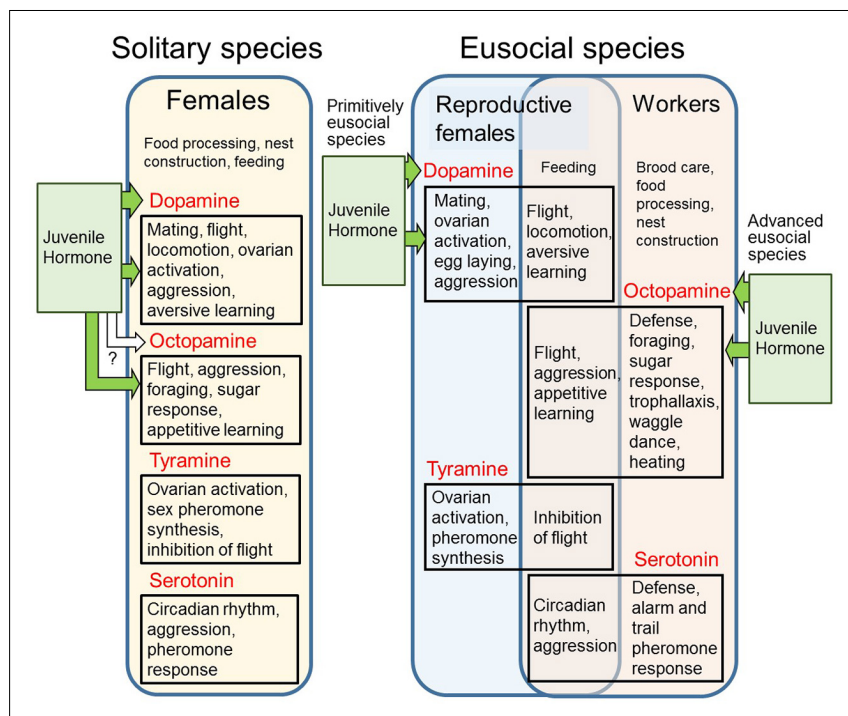

FIGURE 4 | Decoupling the multiple roles of biogenic amines into each phenotype in eusocial species. Multiple roles of biogenic amines in solitary and eusocial species are presented. Several general behaviors or movements are shared between both reproductive females and workers in eusocial species (overlapping area). Juvenile hormone regulates dopamine in solitary and primitively eusocial species, whereas it regulates octopamine in advanced eusocial species. conserved in primitive eusocial species, whereas $\mathrm{JH}$ promotes age-polyethism in non-reproductives in advanced eusocial hymenopteran species (Figure 1). In advanced eusocial species, loss of $\mathrm{JH}$ reproductive function leads to the $\mathrm{SFH}$, whereas the evidence contradicts the OGPH because the $\mathrm{JH}$ reproductive function is not conserved in reproductive individuals. In contrast, the evidence of $\mathrm{JH}$ foraging function in solitary species does not support SFH, rather it fits the situation for OGPH. Interestingly, the reproductive function of dopamine and foraging function of octopamine are widely conserved in solitary to advanced eusocial species. The function expressed in a single individual in solitary species was decoupled into queens and workers in eusocial species, supporting the OGPH. Corresponding to this function, $\mathrm{JH}$ regulates dopamine in reproductive individuals in primitive eusocial species (see section "Social Factors Affecting Dopamine Levels in the Brain"), whereas it is positioned upstream of octopamine in non-reproductives in advanced eusocial species (see section "Social Behaviors and Physiology Mediated by Biogenic Amines") (Figure 4). This rewiring of the signal transduction networks between $\mathrm{JH}$ and biogenic amines can explain the mechanism underlying the shift of $\mathrm{JH}$ function from a gonadotropin to a regulator of worker foraging and might make it possible to regulate reproduction in response to various social stimuli.

\section{PERSPECTIVE}

are mainly mediated by octopamine and serotonin (Farooqui, 2012; see section "Division of Labor Among Workers"). Equivalent roles of dopamine in reproduction (mating and ovarian activation) (see section "Reproductive Function of Dopamine in Solitary Insects") and octopamine in foraging (sugar response, appetitive learning, and memory) (Roeder, 2005; Farooqui, 2012) are found in a single individual in solitary species. Given such preadaptation, the OGPH would be supported (Figure 4). There are, however, several general behaviors or movements that are shared between both reproductives and non-reproductives in eusocial insects. For example, flight behavior is necessary not only for foraging in non-reproductives but also for nuptial flight in reproductives. Given that octopamine and dopamine are tightly related with flight (reviewed by Roeder, 2005; Farooqui, 2012, see sections "Reproductive Division of Labor and Worker Reproduction" and "Division of Labor Among Workers"), the roles of these monoamines might be shared between both reproductives and non-reproductives. Thus, specialization of behavior might require and/or renounce particular sets of aminergic function originated from a pool of ancestral aminergic function.

Generally, in adult insects, $\mathrm{JH}$ is involved in physiology and behaviors for both reproductive and non-reproductive states in solitary species (Hartfelder, 2000; Raikhel et al., 2005; Kapheim and Johnson, 2017; Trumbo, 2018). JH is a primary regulator of reproduction, including ovarian activity and mating behaviors (Hartfelder, 2000; Raikhel et al., 2005) with dopamine function, and is also involved in foraging, including sugar response and learning (Kapheim and Johnson, 2017; Trumbo, 2018; Figure 4). In eusocial hymenopterans, the reproductive function of $\mathrm{JH}$ is
Biogenic amines are broadly present in the nervous systems of invertebrates, modulating their behaviors and reproduction. A limited number of substances can regulate diverse behaviors in eusocial hymenopterans by local secretion in the CNS, or by combining the effects of several monoamines, or their dose-dependent effects. Reports on the behavioral effects of biogenic amines are increasing, although the regulatory systems of biogenic amines, including their interactions with hemolymph hormones or signaling molecules, remain unclear. Important topics for future research include: (i) more functional validation of the biogenic amines associated with social behaviors; (ii) clarification of the "crosstalk" with other physiological mechanisms in signal transduction and regulatory networks; and (iii) widely comparative studies of females in solitary, facultative, and primitive eusocial species as a model of the ancestral mode of reproductive physiology. Taxa-wide comparative studies incorporating phylogenetic information must be efficacious so that the preadaptation of physiological mechanisms and its roles in social evolution can be understood. Comparative studies would also be necessary to reveal both the generality and specificity of physiological mechanisms for social characters across taxa.

\section{CONCLUSION}

The OGPH assumes the physiological decoupling of ovarian cycles and behavior into reproductive and non-reproductive states. The multiple roles of biogenic amines in social behavior and reproduction provide evidence for this hypothesis. Dopaminergic signaling has a pivotal role in the formation of 
reproductive skew irrespective of the social system, whereas octopaminergic signaling contributes largely to non-reproductive social behaviors. These roles of biogenic amines occur in the neuroendocrine system throughout the life cycle of solitary species, supporting the OGPH. JH promotes reproduction with dopamine in primitive eusocial species, whereas it regulates non-reproductive social behaviors with octopamine in advanced eusocial species. Thus, the signal transduction networks between $\mathrm{JH}$ and biogenic amines have been rewired in advanced eusocial species, which makes it possible for these species to regulate their reproduction in response to various social and environmental stimuli.

\section{AUTHOR CONTRIBUTIONS}

All authors listed have made a substantial, direct and intellectual contribution to the work, and approved it for publication. KS

\section{REFERENCES}

Agrahari, M., and Gadagkar, R. (2003). Juvenile hormone accelerates ovarian development and does not affect age polyethism in the primitively eusocial wasp, Ropalidia marginata. J. Insect Physiol. 49, 217-222. doi: 10.1016/S00221910(02)00268-8

Amdam, G. V., Norberg, K., Fondrk, M. K., and Page, R. E. (2004). Reproductive ground plan may mediate colony-level selection effects on individual foraging behavior in honey bees. Proc. Natl Acad. Sci. U.S.A. 101, 11350-11355. doi: 10.1073/pnas.0403073101

Amdam, G. V., and Page, R. E. (2010). The developmental genetics and physiology of honeybee societies. Anim. Behav. 79, 973-980. doi: 10.1016/j.anbehav.2010. 02.007

Amsalem, E., Teal, P., Grozinger, C. M., and Hefetz, A. (2014). Precocene-I inhibits juvenile hormone biosynthesis, ovarian activation, aggression and alters sterility signal production in bumble bee (Bombus terrestris) workers. J. Exp. Biol. 217, 3178-3185. doi: 10.1242/jeb.107250

Aonuma, H. (2020). Serotonergic control in initiating defensive responses to unexpected tactile stimuli in the trap-jaw ant Odontomachus kuroiwae. J. Exp. Biol. 223:jeb228874. doi: 10.1242/jeb. 228874

Aonuma, H., and Watanabe, T. (2012a). Changes in the content of brain biogenic amine associated with early colony establishment in the queen of the ant, Formica japonica. PLoS One 7:e43377. doi: 10.1371/journal.pone.0043377

Aonuma, H., and Watanabe, T. (2012b). Octopaminergic system in the brain controls aggressive motivation in the ant, Formica japonica. Acta Biol. Hung. 63, 63-68. doi: 10.1556/ABiol.63.2012.Suppl.2.6

Argue, K. J., Yun, A. J., and Neckameyer, W. S. (2013). Early manipulation of juvenile hormone has sexually dimorphic effects on mature adult behavior in Drosophila melanogaster. Horm. Behav. 64, 589-597. doi: 10.1016/j.yhbeh.2013. 08.018

Arnold, G., Budharugsa, S., and Masson, C. (1988). Organization of the antennal lobe in the queen honey bee, Apis mellifera L. (Hymenoptera: Apidae). Int. J. Insect Morphol. Embryol. 17, 185-195. doi: 10.1016/0020-7322(88)90 036-0

Asencot, M., and Lensky, Y. (1988). The effect of soluble sugars in stored royal jelly on the differentiation of female honey bee (Apis mellifera L.) larvae to queens. Insect Biochem. 18, 127-133. doi: 10.1016/0020-1790(88)90016-9

Bai, H., and Palli, S. R. (2016). Identification of G protein-coupled receptors required for vitellogenin uptake into the oocytes of the red flour beetle, Tribolium castaneum. Sci. Rep. 6:27648. doi: 10.1038/srep27648

Baier, A., Wittek, B., and Brembs, B. (2002). Drosophila as a new organism for the neurobiology of aggression? J. Exp. Biol. 205, 1233-1240.

Baracchi, D., Cabiol, A., Devaud, J., Haase, A., d'Ettorre, P., and Giurfa, M. (2020). Pheromone components affect motivation and induce persistent modulation wrote the majority of the manuscript and other authors edited the manuscript on their expertise.

\section{FUNDING}

This work was supported by the JSPS KAKENHI Grant Numbers JP17K07491 and JP20K06077 to KS, 19H04913 and JK17K19381 to YO, JP25251041 to TM, JK16K14865 and JK17H01249 to KT, JK15H02652 and JK15H04425 to HS and KT, and JST CREST Grant Number JPMJCR14D5 to HA.

\section{ACKNOWLEDGMENTS}

We thank M. J. West-Eberhard for her useful comments on an earlier version of the manuscript.

of associative learning and memory in honey bees. Commun. Biol. 3:447. doi: 10.1038/s42003-020-01183-x

Barron, A. B., Maleszka, R., Vander Meer, R. K., and Robinson, G. (2007). Octopamine modulates honey bee dance behavior. Proc. Natl. Acad. Sci. U.S.A. 104, 1703-1707. doi: 10.1073/pnas.0610506104

Barth, R. H., Lester, L. J., Sroka, P., Kessler, T., and Hearn, R. (1975). Juvenile hormone promotes dominance behavior and ovarian development in social wasps (Polistes annularis). Exprientia 31, 691-692. doi: 10.1007/BF01944632

Beggs, K. T., Glendining, K. A., Marechal, N. M., Vergoz, V., Nakamura, I., Slessor, K. N., et al. (2007). Queen pheromone modulates brain dopamine function in worker honey bees. Proc. Natl. Acad. Sci. U.S.A. 104, 2460-2464. doi: 10.1073/ pnas.0608224104

Beggs, K. T., and Mercer, A. R. (2009). Dopamine receptor activation by honey bee queen pheromone. Curr. Biol. 19, 1206-1209. doi: 10.1016/j.cub.2009.05.051

Bell, W. J. (1973). Factors controlling initiation of vitellogenesis in a primitively social bee, Lasioglossum zephyrum (Hymenoptera: Halictidae). Insect. Soc. 20, 253-260. doi: 10.1007/BF02223194

Berens, A. J., Hunt, J. H., and Toth, A. T. (2015). Comparative transcriptomics of convergent evolution: different genes but conserved pathways underlie caste phenotypes across lineages of eusocial Insects. Mol. Biol. Evol. 32, 690-703. doi: $10.1093 / \mathrm{molbev} / \mathrm{msu} 330$

Bloch, G., Shpigler, H., Wheeler, D. E., and Robinson, G. E. (2009). "Endocrine Influences on the organization of insect societies," in Hormones, Brain, and Behavior, 2nd Edn, eds D. Pfaff, A. Arnold, A. Etgen, S. Fahrbach, R. Moss, and R. Rubin (San Diego, CA: Academic Press), 1028-1068. doi: 10.1016/B978012532104-4/50042-1

Bloch, G., Simon, T., Robinson, G. E., and Hefetz, A. (2000). Brain biogenic amines and reproductive dominance in bumble bees (Bombus terrestris). J. Comp. Physiol. A 186, 261-268. doi: 10.1007/s003590050426

Bohm, M. K. (1972). Effects of environment and juvenile hormone on ovaries of the wasp. Polistes metricus. J. Insect Physiol. 18, 1875-1883. doi: 10.1016/00221910(72)90158-8

Boulay, R., Hooper-Bui, L. M., and Woodring, J. (2001). Oviposition and oogenesis in virgin fire ant females Solenopsis invicta are associated with a high level of dopamine in the brain. Physiol. Entomol. 26, 294-299. doi: 10.1046/j.0307-6962. 2001.00250.x

Boulay, R., Soroker, V., Godzinska, E. J., Hefetz, A., and Lenoir, A. (2000). Octopamine reverses the isolation-induced increase in trophallaxis in the carpenter ant Camponotus fellah. J. Exp. Biol. 203, 513-520.

Brandes, C., Sugawa, M., and Menzel, R. (1990). High-performance liquid chromatography (HPLC) measurement of catecholamines in single honeybee brains reveals caste-specific differences between worker bees and queens in Apis mellifera. Comp. Biochem. Physiol. C 97, 53-57. doi: 10.1016/0742-8413(90) 90171-5 
Brent, C., Peeters, C., Dietmann, V., Crewe, R., and Vargo, E. (2006). Hormonal correlates of reproductive status in the queenless ponerine ant, Streblognathus peetersi. J. Comp. Physiol. A 192, 315-320. doi: 10.1007/s00359-005-0065-6

Brent, C. S., Miyasaki, K., Vuong, C., Miranda, B., Steele, B., Brent, K. G., et al. (2016). Regulatory roles of biogenic amines and juvenile hormone in the reproductive behavior of the western tarnished plant bug (Lygus hesperus). J. Comp. Physiol. B 186, 169-179. doi: 10.1007/s00360-015-0953-1

Brent, C. S., and Vargo, E. (2003). Changes in juvenile hormone biosynthetic rate and whole body content in maturing virgin queens of Solenopsis invicta. J. Insect Physiol. 49, 967-974. doi: 10.1016/S0022-1910(03)00166-5

Carcaud, J., Giurfa, M., and Sandoz, J. (2015). Differential combinatorial coding of pheromones in two olfactory subsystems of the honey bee brain. J. Neurosci. 35 , 4157-4167. doi: 10.1523/JNEUROSCI.0734-14.2015

Chvalova, D., Zdechovanova, L., Vaneckova, H., and Hodkova, M. (2014). Brain norepinephrine identified by mass spectrometry is associated with reproductive status of females of the linden bug Pyrrhocoris apterus. Comp. Biochem. Phys. B 168, 70-75. doi: 10.1016/j.cbpb.2013.11.003

Cook, C. N., Brent, C. S., and Breed, M. D. (2017). Octopamine and tyramine modulate the thermoregulatory fanning responses in honey bees (Apis mellifera). J. Exp. Biol. 220, 1925-1930. doi: 10.1242/jeb.149203

Corona, M., Libbrecht, R., and Wheeler, D. (2016). Molecular mechanisms of phenotypic plasticity in social insects. Curr. Opin. Insect Sci. 13, 55-60. doi: 10.1016/j.cois.2015.12.003

Costa, J. T. (2018). The other insect societies: overview and new directions. Curr. Opin. Insect Sci. 28, 40-49.

Cuvillier-Hot, V., and Lenoir, A. (2006). Biogenic amine levels, reproduction and social dominance in the queenless ant Streblognathus peetersi. Naturwissenschaften 93, 149-153. doi: 10.1007/s00114-006-0086-1

Cuvillier-Hot, V., Lenoir, A., and Peeters, C. (2004). Reproductive monopoly enforced by sterile police workers in a queenless ant. Behav. Ecol. 15, 970-975. doi: 10.1093/beheco/arh072

d'Ettorre, P., Heinze, J., Schulz, C., Francke, W., and Ayasse, M. (2004). Does she smell like a queen? Chemoreception of a cuticular hydrocarbon signal in the ant Pachycondyla inversa. J. Exp. Biol. 207, 1085-1091. doi: 10.1242/jeb.00865

Dombroski, T. C. D., Simoes, Z. J. P., and Bitondi, M. M. G. (2003). Dietary dopamine causes ovary activation in queenless Apis mellifera workers. Apidologie 34, 281-289. doi: 10.1051/apido:2003024

Evans, P. D. (1980). Biogenic amines in the insect nervous system. Adv. Insect Physiol. 15, 317-473. doi: 10.1016/S0065-2806(08)60143-5

Farkhary, S. I., Sasaki, K., Hayashi, S., Harano, K., Koyama, S., and Satoh, T. (2017). Fighting and stinging responses are affected by a dopamine receptor blocker flupenthixol in honey bee virgin queens. J. Insect Behav. 30, 717-727. doi: 10.1007/s10905-017-9650-0

Farkhary, S. I., Sasaki, K., Hayashi, S., Harano, K., Koyama, S., and Satoh, T. (2019). Suppression of flight activity by a dopamine receptor antagonist in honey bee (Apis mellifera) virgin queens and workers. J. Insect Behav. 32, 218-224. doi: 10.1007/s10905-019-09728-7

Farooqui, T. (2012). Review of octopamine in insect nervous systems. Open Access Insect Physiol. 4, 1-17. doi: 10.2147/OAIP.S20911

Fuchs, S., Behrends, V., Bundy, J. G., Crisanti, A., and Nolan, T. (2014). Phenylalanine metabolism regulates reproduction and parasite melanization in the malaria mosquito. PLoS One 9:e84865. doi: 10.1371/journal.pone.0084865

Fussenecker, B. L., Smith, B. H., and Mustard, J. A. (2006). Octopamine and tyramine influence the behavioral profile of locomotor activity in the honey bee (Apis mellifera). J. Insect Physiol. 52, 1083-1092. doi: 10.1016/j.jinsphys.2006. 07.008

Giray, T., Giovanetti, M., and West-Eberhard, M. J. (2005). Juvenile hormone, reproduction, and worker behavior in the neotropical social wasp Polistes canadensis. Proc. Natl. Acad. Sci. U.S.A. 102, 3330-3335. doi: 10.1073/pnas. 0409560102

Groh, C., and Rössler, W. (2008). Caste-specific postembryonic development of primary and secondary olfactory centers in the female honeybee brain. Arthropod Struct. Dev. 37, 459-468. doi: 10.1016/j.asd.2008.04.001

Gruntenko, N. E., Laukhina, O. V., and Rauschenbach, I. Y. (2012). Role of D1- and D2-like receptors in age-specific regulation of juvenile hormone and 20-hydroxyecdysone levels by dopamine in Drosophila. J. Insect Physiol. 58, 1534-1540. doi: 10.1016/j.jinsphys.2012.09.005
Gullan, P. J., and Cranston, P. S. (2014). The Insects: An outline of Entomology, 5th Edn. West Sussex: Wiley-Blackwell.

Harano, K., Sasaki, M., Nagao, T., and Sasaki, K. (2008). Dopamine influences locomotor activity in honeybee queens: implications for a behavioural change after mating. Physiol. Entomol. 33, 395-399.

Harris, J. W., and Woodring, J. (1995). Elevated brain dopamine levels associated with ovary development in queenless worker honey bees (Apis mellifera L.). Comp. Biochem. Physiol. C 111, 271-279. doi: 10.1016/0742-8413(95)00048-S

Harris, J. W., and Woodring, J. (1999). Effects of dietary precursors to biogenic amines on the behavioural response from groups of caged worker honey bees (Apis mellifera) to the alarm pheromone component isopentyl acetate. Physiol. Entomol. 24, 285-291. doi: 10.1046/j.1365-3032.1999.00141.x

Hartfelder, K. (2000). Insect juvenile hormone: from status quo to high society. Braz. J. Med. Biol. Res. 33, 157-177.

Haydak, M. H. (1970). Honey bee nutrition. Annu. Rev. Entomol. 15, 143-156. doi: 10.1146/annurev.en.15.010170.001043

Hojo, M. K., Pierce, N. E., and Tsuji, K. (2015). Lycaenid caterpillar secretions manipulate attendant ant behavior. Curr. Biol. 25, 2260-2264. doi: 10.1016/j. cub.2015.07.016

Hunt, J. H. (2007). The Evolution of Social Wasps. Oxford: Oxford University Press.

Hunt, J. H. (2012). A conceptual model for the origin of worker behavior and adaptation of eusociality. J. Evol. Biol. 25, 1-19. doi: 10.1111/j.1420-9101.2011. 02421.x

Jandt, J. M., and Toth, A. L. (2015). Physiological and genomic mechanisms of social organization in wasps (family: Vespidae). Adv. Insect Physiol. 48, 95-130.

Jindra, M., Palli, S. R., and Riddiford, L. M. (2013). The juvenile hormone signaling pathway in insect development. Annu. Rev. Entomol. 58, 181-204.

Kamakura, M. (2011). Royalactin induces queen differentiation in honeybees. Nature 473, 478-483. doi: 10.1038/nature10093

Kamhi, J. F., Arganda, S., Moreau, C. S., and Traniello, J. F. A. (2017). Origin of aminergic regulation of behavior in complex insect social systems. Front. Syst. Neurosci. 11:74. doi: 10.3389/fnsys.2017.00074

Kamhi, J. F., Nunn, K., Robson, S. K. A., and Traniello, J. F. A. (2015). Polymorphism and division of labour in a socially complex ant: neuromodulation of aggression in the Australian weaver ant, Oecophylla smaragdina. Proc. R. Soc. B 282:20150704. doi: 10.1098/rspb.2015.0704

Kapheim, K. M., and Johnson, M. M. (2017). Support for the reproductive ground plan hypothesis in a solitary bee: links between sucrose response and reproductive status. Proc. R. Soc. B 284:20162406. doi: 10.1098/rspb.2016.2406

Kelstrup, H. C., Hartfelder, K., Esterhuizen, N., and Wossler, T. C. (2017). Juvenile hormone titers, ovarian status and epicuticular hydrocarbons in gynes and workers of the paper wasp Belonogaster longitarsus. J. Insect Physiol. 98, 83-92. doi: 10.1016/j.jinsphys.2016.11.014

Kelstrup, H. C., Hartfelder, K., Nascimento, F. S., and Riddiford, L. M. (2014a). Reproductive status, endocrine physiology and chemical signaling in the Neotropical, swarm-founding eusocial wasp Polybia micans. J. Exp. Biol. 217, 2399-2410. doi: 10.1242/jeb.096750

Kelstrup, H. C., Hartfelder, K., Nascimento, F. S., and Riddiford, L. M. (2014b). The role of juvenile hormone in dominance behavior, reproduction and cuticular pheromone signaling in the caste-flexible epiponine wasp, Synoeca surinama. Front. Zool. 11:78. doi: 10.1186/s12983-014-0078-5

Kelstrup, H. C., Hartfelder, K., and Wossler, T. C. (2015). Polistes smithii vs. Polistes dominula: the contrasting endocrinology and epicuticular signaling of sympatric paper wasps in the field. Behav. Ecol. Sociobiol. 69, 2043-2058. doi: 10.1007/s00265-015-2015-9

Kostowski, W., and Tarchalska, B. (1972). The effects of some drugs affecting brain 5-HT on the aggressive behaviour and spontaneous electrical activity of the central nervous system of the ant, Formica rufa. Brain Res. 38, 143-149. doi: 10.1016/0006-8993(72)90595-1

Kostowski, W., and Tarchalska-Krynska, B. (1975). Aggressive behavior and brain serotonin and catecholamines in ants (Formica rufa). Pharm. Biochem. Behav. 3, 717-719.

Lange, A. B. (2009). Tyramine: from octopamine precursor to neuroactive chemical in insects. Gen. Comp. Endocrinol. 162, 18-26. doi: 10.1016/j.ygcen.2008.05.021

Leimer, O., Hartfelder, K., Laubichler, M. D., and Page, R. E. (2012). Development and evolution of caste dimorphism in honeybees - a modeling approach. Ecol. Evol. 2, 3098-3109. doi: 10.1002/ece3.414 
Liming, W., Jinhui, Z., Xiaofeng, X., Li, X., and Jing, Z. (2009). Fast determination of 26 amino acids and their content changes in royal jelly during storage using ultra-performance liquid chromatography. J. Food Comp. Anal. 22, 242-249. doi: $10.1016 /$ j.jfca.2008.10.022

Matsuyama, S., Nagao, T., and Sasaki, K. (2015). Consumption of tyrosine in royal jelly increases brain levels of dopamine and tyramine and promotes transition from normal to reproductive workers in queenless honey bee colonies. Gen. Comp. Endocrinol. 211, 1-8.

McCabe, S. I., Ferro, M. W. B., Farina, W. M., and Hrncir, M. (2017). Doseand time-dependent effects of oral octopamine treatments on the sucrose responsiveness in stingless bees (Melipona scutellaris). Apidologie 48, 1-7. doi: 10.1007/s13592-016-0442-x

Michener, C. D. (1974). The Social Behavior of the Bees. Cambridge, MA: Harvard University Press.

Muscedere, M. L., Johnson, N., Gillis, B. C., Kamhi, J. F., and Traniello, J. F. A. (2012). Serotonin modulates worker responsiveness to trail pheromone in the ant Pheidole dentate. J. Comp. Physiol. A 198, 219-227. doi: 10.1007/s00359011-0701-2

Neckameyer, W. S. (1996). Multiple roles for dopamine in Drosophila development. Dev. Biol. 176, 209-219. doi: 10.1006/dbio.1996.0128

Nijhout, H. F. (1994). Insect Hormones. Princeton, NJ: Princeton University Press.

Nouvian, M., Mandal, S., Jamme, C., Claudianos, C., d'Ettorre, P., Reinhard, J., et al. (2018). Cooperative defence operates by social modulation of biogenic amine levels in the honey bee brain. Proc. R. Soc. B 285:20172653.

O’Donnell, S. (1998). Reproductive caste determination in eusocial wasps (Hymenoptera: Vespidae). Annu. Rev. Entomol. 43, 323-346. doi: 10.1146/ annurev.ento.43.1.323

O'Donnell, S., and Jeanne, R. L. (1993). Methoprene accelerates age polythism in workers of a social wasp (Polybia occidentailis). Physiol. Entomol. 18, 189-194. doi: 10.1111/j.1365-3032.1993.tb00467.x

Okada, Y., Sasaki, K., Miyazaki, S., Shimoji, H., Tsuji, K., and Miura, T. (2015). Social dominance and reproductive differentiation mediated by dopaminergic signaling in a queenless ant. J. Exp. Biol. 218, 1091-1098.

Pastor, D., Artigas, F., Martinez, E., and Belles, X. (1991). Brain levels of 5hydroxytryptamine and dopamine in Blattela germanica adult females during the first gonadotrophic cycle. Biogenic Amines 8, 109-114.

Pendleton, R. G., Robinson, N., Roychowdhury, R., Rasheed, A., and Hillman, R. (1996). Reproduction and development in Drosophila are dependent upon catecholamines. Life Sci. 59, 2083-2091. doi: 10.1016/s0024-3205(96) 00562-0

Peng, T., Schroeder, M., and Grüter, C. (2020). Octopamine increases individual and collective foraging in a neotropical stingless bee. Biol. Lett. 16:20200238. doi: $10.1098 / \mathrm{rsbl} .2020 .0238$

Penick, C. A., Brent, C. S., Dolezal, K., and Liebig, J. (2014). Neurohormonal changes associated with ritualized combat and the formation of a reproductive hierarchy in the ant Harpegnathos saltator. J. Exp. Biol. 217, 1496-1503. doi: 10.1242/jeb.098301

Penick, C. A., Liebig, J., and Brent, C. S. (2011). Reproduction, dominance, and caste: endocrine profiles of queens and workers of the ant Harpegnathos saltator. J. Comp. Physiol. A. 197, 1063-1071. doi: 10.1007/s00359-011-0667-0

Pinto, L. Z., Bitondi, M. M. G., and Simoes, Z. L. P. (2000). Inhibition of vitellogenin synthesis in Apis mellifera workers by a juvenile hormone analogue, pyriproxyfen. J. Insect Physiol. 46, 153-160. doi: 10.1016/S0022-1910(99)00 111-0

Raikhel, A., Brown, M., and Bells, X. (2005). "Hormonal control of reproductive processes," in Comprehensive Molecular Insect Science, Vol. vol. 3, eds L. Gilbert, K. Iatrou, and S. Gill (Oxford: Elsevier), 433-491. doi: 10.1016/B0-44-4519246/00040-5

Reim, T., and Scheiner, R. (2014). Division of labour in honey bees: age- and taskrelated changes in the expression of octopamine receptor genes. Insect Mol. Biol. 23, 833-841. doi: 10.1111/imb.12130

Robinson, G. E., Heuser, L. M., LeConte, Y., Lenquette, F., and Hollingworth, R. M. (1999). Neurochemicals aid bee nestmate recognition. Nature 399, 534-535. doi: $10.1038 / 21095$

Robinson, G. E., Strambi, C., Strambi, A., and Huang, Z. (1992). Reproduction in worker honey bees is associated with low juvenile hormone titers and rates of biosynthesis. Gen. Comp. Physiol. 87, 471-480. doi: 10.1016/0016-6480(92) 90055-O
Robinson, G. E., and Vargo, E. (1997). Juvenile hormone in adult eusocial Hymenoptera: gonadotropin and behavioral pacemaker. Arch. Insect Biochem. Physiol. 35, 559-583.

Roeder, T. (2005). Tyramine and octopamine: ruling behavior and metabolism. Ann. Rev. Entomol. 50, 447-477. doi: 10.1146/annurev.ento.50.071803.130404

Röseler, P. F. (1977). Juvenile hormone control of oögenesis in bumblebee workers, Bombus terrestris. J. Insect Physiol. 23, 985-992. doi: 10.1016/0022-1910(77) 90126-3

Salomon, M., Malka, O., Vander Meer, R. K., and Hefetz, A. (2012). The role of tyramine and octopamine in the regulation of reproduction in queenless worker honeybees. Naturwissenschaften 99, 123-131. doi: 10.1007/s00114-011-0877-x

Sasaki, K., and Harada, M. (2020). Dopamine production in the brain is associated with caste-specific morphology and behavior in an artificial intermediate honey bee caste. PLoS One 15:e244140. doi: 10.1371/journal.pone.0244140

Sasaki, K., and Harano, K. (2007). Potential effects of tyramine on the transition to reproductive workers in honeybees (Apis mellifera L.). Physiol. Entomol. 32, 194-198.

Sasaki, K., Matsuyama, H., Morita, N., and Ono, M. (2017). Caste differences in the association between dopamine and reproduction in the bumble bee Bombus ignitus. J. Insect Physiol. 103, 107-116. doi: 10.1016/j.jinsphys.2017.10.013

Sasaki, K., Matsuyama, S., Harano, K., and Nagao, T. (2012). Caste differences in dopamine-related substances and dopamine supply in the brains of honeybees (Apis mellifera L.). Gen. Comp. Endocrinol. 178, 46-53.

Sasaki, K., and Nagao, T. (2001). Distribution and levels of dopamine and its metabolites in brains of reproductive workers in honeybees. J. Insect Physiol. 47, 1205-1216. doi: 10.1016/S0022-1910(01)00105-6

Sasaki, K., and Nagao, T. (2002). Brain tyramine and reproductive states of workers in honeybees. J. Insect Physiol. 48, 1075-1085. doi: 10.1016/S0022-1910(02) 00200-7

Sasaki, K., Ugajin, A., and Harano, K. (2018). Caste-specific development of the dopaminergic system during metamorphosis in female honey bees. PLoS One 13:e0206624. doi: 10.1371/journal.pone.0206624

Sasaki, K., Yamasaki, K., and Nagao, T. (2007). Neuro-endocrine correlates of ovarian development and egg-laying behaviors in the primitively eusocial wasp (Polistes chinensis). J. Insect Physiol. 53, 940-949. doi: 10.1016/j.jinsphys.2007. 03.006

Sasaki, K., Yamasaki, K., Tsuchida, K., and Nagao, T. (2009). Gonadotropic effects of dopamine in isolated workers of the primitively eusocial wasp, Polistes chinensis. Naturwissenschaften 96, 625-629.

Sasaki, K., Yokoi, K., and Toga, K. (2021). Bumble bee queens activate dopamine production and gene expression in nutritional signaling pathways in the brain. Sci. Rep. 11:5526. doi: 10.1038/s41598-021-84992-2

Scheiner, R., Plückhahn, S., Öney, B., Blenau, W., and Erber, J. (2002). Behavioral pharmacology of octopamine, tyramine and dopamine in honey bees. Behav. Brain Res. 136, 545-553. doi: 10.1016/S0166-4328(02)00205-X

Schulz, D. J., and Robinson, G. E. (1999). Biogenic amines and division of labor in honey bee colonies: behaviorally related changes in the antennal lobes and age-related changes in the mushroom bodies. J. Comp. Physiol. A 184, 481-488. doi: $10.1007 / \mathrm{s} 003590050348$

Schulz, D. J., and Robinson, G. E. (2001). Octopamine influences division of labor in honey bee colonies. J. Comp. Physiol. A 187, 53-61. doi: 10.1007/ s003590000177

Schulz, D. J., Sullivan, J. P., and Robinson, G. E. (2002). Juvenile hormone and octopamine in the regulation of division of labor in honey bee colonies. Horm. Behav. 42, 222-231. doi: 10.1006/hbeh.2002.1806

Seid, M. A., and Traniello, J. F. A. (2005). Age-related changes in biogenic amines in individual brains of the ant Pheidole dentata. Naturwissenschaften 92, 198-201. doi: 10.1007/s00114-005-0610-8

Shimoji, H., Aonuma, H., Miura, T., Tsuji, K., Sasaki, K., and Okada, Y. (2017). Queen contact and among-worker interactions dually suppress worker brain dopamine as a potential regulator of reproduction in an ant. Behav. Ecol. Sociobiol. 71:35. doi: 10.1007/s00265-016-2263-3

Shpigler, H., Amsalem, E., Huang, Z. Y., Cohen, M., Siegel, A. J., Hefetz, A., et al. (2014). Gonadotropic and physiological functions of juvenile hormone in bumblebee (Bombus terrestris) workers. PLoS One 9:e100650. doi: 10.1371/ journal.pone.0100650

Smith, A. R., Kapheim, K. M., Perez-Ortega, B., Brent, C. S., and Wcislo, W. T. (2013). Juvenile hormone levels reflect social opportunities in the facultatively 
eusocial sweat bee Magalopta genalis (Hymenoptera: Halictidae). Horm. Behav. 63, 1-4. doi: 10.1016/j.yhbeh.2012.08.012

Snodgrass, R. E. (1956). Anatomy of the Honey Bee. Ithaca, NY: Cornell University Press.

Solís, C. R., and Strassmann, J. E. (1990). Presence of brood affects caste differentiation in the social wasp, Polistes exclamans Viereck (Hymenoptera: Vespidae). Funct. Ecol. 4, 531-541. doi: 10.2307/2389321

Sommer, K., Hölldobler, B., and Rembold, H. (1993). Behavioral and physiological aspects of reproductive control in the Diacamma species from Malaysia (Formicidae, Ponerinae). Ethology 94, 162-170. doi: 10.1111/j.1439-0310.1993. tb00556.x

Stevenson, P. A., Dyakonova, V., Rillich, J., and Schildberger, K. (2005). Octopamine and experience-dependent modulation of aggression in crickets. J. Neurosci. 25, 1431-1441. doi: 10.1523/JNEUROSCI. 4258-04.2005

Sullivan, J. P., Jassim, O., Fahrbach, S. E., and Robinson, G. E. (2000). Juvenile hormone paces behavioral development in the adult worker honey bee. Horm. Behav. 37, 1-14. doi: 10.1006/hbeh.1999.1552

Suryanarayanan, S., Hermanson, J. C., and Jeanne, R. L. (2011). A mechanical signal biases caste development in a social wasp. Curr. Biol. 21, 231-235. doi: 10.1016/j.cub.2011.01.003

Taylor, D. J., Robinson, G. E., Logan, B. J., Laverty, R., and Mercer, A. R. (1992). Changes in brain amine levels associated with the morphological and behavioural development of the worker honeybee. J. Comp. Physiol. A 170, 715-721. doi: 10.1007/BF00198982

Tibbetts, E. A., Izzo, A., and Huang, Z. Y. (2011a). Behavioral and physiological factors associated with juvenile hormone in Polistes wasp foundresses. Behav. Ecol. Sociobiol. 65, 1123-1131. doi: 10.1007/s00265-010-1126-6

Tibbetts, E. A., Levy, S., and Donajkowski, K. (2011b). Reproductive plasticity in Polistes paper wasp workers and the evolutionary origins of sociality. J. Insect Physiol. 57, 995-999. doi: 10.1016/j.jinsphys.2011.04.016

Tibbetts, E. A., Mettler, A., and Donajkowski, K. (2013a). Nutrition-dependent fertility response to juvenile hormone in non-social Euodynerus foraminatus wasps and the evolutionary origin of sociality. J. Insect Physiol. 59, 339-344. doi: $10.1016 /$ j.jinsphys.2012.11.010

Tibbetts, E. A., Vernier, C., and Jinn, J. (2013b). Juvenile hormone influences precontest assessment behaviour in Polistes dominulus paper wasps. Anim. Behav. 85, 1177-1181. doi: 10.1016/j.anbehav.2013.03.003

Toth, A. L., and Rehan, S. M. (2017). Molecular evolution of insect sociality: an ecoevo-devo perspective. Annu. Rev. Entomol. 62, 419-442. doi: 10.1146/annurevento-031616-035601

Townsend, G. F., and Lucas, C. C. (1940). The chemical nature of royal jelly. Biochem. J. 34, 1155-1162.

Trumbo, S. T. (2018). Juvenile hormone and parental care in subsocial insects: implications for the role of juvenile hormone in the evolution of sociality. Curr. Opin. Insect Sci. 28, 13-18. doi: 10.1016/j.cois.2018.04.001
Tsuchida, K., Saigo, T., Asai, K., Okamoto, T., Ando, M., Ando, T., et al. (2020). Reproductive workers insufficiently signal their reproductive ability in a paper wasp. Behav. Ecol. 31, 577-590. doi: 10.1093/beheco/arz212

Van Oystaeyen, A., Oliveira, R. C., Holman, L., van Zweden, J. S., Romero, C., Oi, C. A., et al. (2014). Conserved class of queen pheromones stops social insect workers from reproducing. Science 343, 287-290. doi: 10.1126/science.1244899

Vergoz, V., Lim, J., and Oldroyd, B. P. (2012). Biogenic amine receptor gene expression in the ovarian tissue of the honey bee Apis mellifera. Insect Mol. Biol. 21, 21-29. doi: 10.1111/j.1365-2583.2011.01106.x

Wanner, K. W., Nichols, A. S., Walden, K. K. O., Brockmann, A., Luetje, C. W., and Robertson, H. M. (2007). A honey bee odorant receptor for the queen substance 9-oxo-2-decenoic acid. Proc. Natl Acad. Sci. U.S.A. 104, 14383-14388. doi: 10.1073/pnas.0705459104

Wasieleski, O., Wojciechowicz, T., Giejdasz, K., and Krishnan, N. (2011). Influence of methoprene and temperature on diapause termination in adult females of the over-wintering solitary bee, Osmia rufa L. J. Insect Physiol. 57, 1682-1688. doi: 10.1016/j.jinsphys.2011.09.002

West-Eberhard, M. J. (1996). "Wasp societies as microcosms for the study of development and evolution," in Natural History and Evolution of Paper Wasps, eds S. Turillazzi and M. J. West-Eberhard (Oxford: Oxford University Press), 290-317.

Wicker-Thomas, C., and Hamann, M. (2008). Interaction of dopamine, female pheromones, locomotion and sex behavior in Drosophila melanogaster. J. Insect Physiol. 54, 1423-1431. doi: 10.1016/j.jinsphys.2008.08.005

Wilde, J. D., and Beetsma, J. (1982). The physiology of caste development in social insects. Adv. Insect Physiol. 16, 167-246. doi: 10.1016/S0065-2806(08)60154-X

Wilson, E. O. (1971). The Insect Societies. Cambridge, MA: Belknap Press of Harvard University Press.

Winston, M. L. (1987). The Biology of the Honey Bee. Cambridge, MA: Harvard University Press.

Yoshimura, H., Yamada, Y. Y., and Sasaki, K. (2021). Identification of biogenic amines involved in photoperiod-dependent caste-fate determination during the adult stage in a temperate paper wasp. J. Insect Physiol. 131:104223. doi: 10.1016/j.jinsphys.2021.104223

Conflict of Interest: The authors declare that the research was conducted in the absence of any commercial or financial relationships that could be construed as a potential conflict of interest.

Copyright (c) 2021 Sasaki, Okada, Shimoji, Aonuma, Miura and Tsuji. This is an open-access article distributed under the terms of the Creative Commons Attribution License (CC BY). The use, distribution or reproduction in other forums is permitted, provided the original author(s) and the copyright owner(s) are credited and that the original publication in this journal is cited, in accordance with accepted academic practice. No use, distribution or reproduction is permitted which does not comply with these terms. 